\title{
Impactos das redes sociais digitais na saúde mental de adolescentes e jovens
}

\author{
Karlla Danielly de Souza, Mônica Ximenes Carneiro da Cunha
}

Coordenação de Informática - Instituto Federal de Alagoas (IFAL) - Campus Maceió

CEP 57020-600 - Maceió - AL - Brasil

karlladanielly94@hotmail.com, monica@ifal.edu.br

\begin{abstract}
This study examined the digital social networks impacts on the adolescents and young people mental health. This exploratory research presents a mixed approach with two steps. The qualitative step involved the questionnaires application to five psychologists. In turn, the quantitative stage consisted of a survey with 566 adolescents and young people. The results obtained proved that there are relationships between technological dependence and the psychological health of adolescents and young people. And design app proposal aimed at assisting teachers and school psychologists in detecting psychological problems signs in this target audience.
\end{abstract}

Resumo. O presente trabalho teve como objetivo examinar os impactos das redes sociais digitais na saúde mental dos adolescentes e jovens. Esta pesquisa exploratória apresenta uma abordagem mista, composta por duas etapas. A etapa qualitativa envolveu a aplicação de questionários a cinco psicólogos. Por sua vez, a etapa quantitativa consistiu em um survey com 566 adolescentes e jovens. Os resultados obtidos comprovaram que há relação entre a dependência tecnológica e a saúde psicológica de adolescentes e jovens. E serviram para respaldar a proposta de um aplicativo voltado para auxiliar professores e psicólogos escolares na deteç̧ão de indícios de problemas psicológicos neste público-alvo.

\section{Introdução}

Uma pesquisa da ONU (2017) apresentou o Brasil como o quarto país com maior número de usuários de internet, 120 milhões, ficando atrás apenas de Estados Unidos, Índia e China. Silva e Silva (2017) alertaram que o uso da internet todos os dias pode causar conflitos familiares decorrentes da falta de diálogo, além de levar a relações superficiais, dificuldades de aprendizagem, transtornos de ansiedade e déficit de atenção.

Entre os jovens, o uso da tecnologia pode tornar-se uma dependência, especialmente no tocante a redes sociais. Através do trabalho de Silva (2016) foi possível concluir que é na rede onde os pré-julgamentos são realizados, e os relacionamentos são declarados e exibidos em "público" diante de pessoas muitas vezes desconhecidas. Essas relações virtuais surgem quase sempre com o objetivo de alcançar o maior número de "amigos" com status manipulados por outros indivíduos, buscando obter o maior número de seguidores, de likes (curtidas) e comentários em suas postagens nas redes sociais. Não obstante, muitas vezes os jovens chegam a excluir postagens por não alcançarem um determinado público. 
O uso excessivo de redes sociais revela um ambiente no qual os jovens agridem verbalmente pessoas com pensamentos e culturas diferentes das suas, que posteriormente podem causar danos psicológicos a outrem. O bullying virtual, as agressões verbais e as mensagens mal interpretadas podem influenciar em mudanças de hábito, discórdias e até desestruturação de famílias, estes são alguns dos fatores que aumentaram as taxas de quadros de depressão (SAMPASA-KANYINGA; HAMILTON, 2015; BLACHNIO, 2015; RADOVIV et al, 2017).

Este trabalho foi motivado pela preocupação com as novas necessidades dos adolescentes no meio virtual, os problemas emocionais causados e/ou divulgados nas mídias, e os possíveis agravantes de distúrbios mentais já existentes. E se estende para o campo da psicologia, trazendo uma análise sobre as influências das redes sociais digitais sobre os comportamentos e saúde mental dos adolescentes e jovens.

As próximas seções deste artigo estão organizadas da seguinte forma: na seção 2 são mencionados alguns trabalhos correlatos; na seção 3 está descrita a metodologia adotada para a pesquisa; na seção 4 são exibidos os resultados e, por fim, são apresentadas as conclusões.

\section{Trabalhos Correlatos}

Gonçalves e Nuemberg (2012) realizaram um estudo de campo, do tipo exploratório qualitativo, envolvendo 10 adolescentes, com objetivo de verificar como o mundo virtual pode influenciar a vida dos adolescentes. O estudo identificou que a internet acentua a falta de interação entre os adolescentes no mundo real pois a tela do computador traz certa segurança, evitando assim frustrações, rejeições e sentimentos que precisam enfrentar na vida real. Desta forma, pode-se dizer que a internet serve como uma fuga da realidade, e que essa dependência precisa de tratamento, principalmente quando interfere diretamente na qualidade de vida do indivíduo.

O trabalho de Silva e Silva (2017) também discutiu, mediante o olhar psicopedagógico, as consequências do uso indiscriminado de tecnologias digitais pelos adolescentes. Foi realizado um estudo bibliográfico de caráter exploratório, com foco nas implicações afetivas, sociais e cognitivas. Os resultados apontaram para conflitos familiares devido ao distanciamento e à falta de diálogo, relações superficiais, dificuldades de aprendizagem decorrentes da dependência da internet, transtornos de ansiedade e déficit de atenção.

Por sua vez, Silva et al. (2017) realizaram um estudo exploratório com 264 estudantes de uma escola estadual, para verificar o tempo de uso de aparelhos tecnológicos pelos adolescentes e sua associação com possíveis sinais de alerta para problemas comportamentais. Os resultaram demonstraram que a maioria dos adolescentes tem acesso à internet e a utiliza diariamente, por mais de 10 horas no dia. Houve um predomínio do uso de smartphone e foi observado que há um sentimento negativo (ansiedade, irritação, apreensão, tédio e falta de concentração) quando os adolescentes são proibidos de usar ou quando ficam longe do aparelho por algum tempo.

Um estudo mais recente realizado por Fialho e Sousa (2019), mediante uma pesquisa qualitativa com 30 participantes, cruzou as narrativas de 15 jovens e 15 pais no objetivo de compreender a utilização das redes sociais pelos jovens e as orientações dadas pelos responsáveis para o uso crítico dessas ferramentas. Os resultados sinalizaram para o tempo excessivo de utilização da internet pelos jovens, em maior proporção para o 
acesso às redes sociais, como: Facebook, Whatsapp, Messenger e Instagram; relação de dependência com a internet e auto-exposição, além da ausência de orientações por parte dos pais e da escola.

Os resultados dos estudos supracitados, das áreas de humanas e saúde, serviram como base para comparar os achados da presente pesquisa.

\section{Metodologia}

A presente pesquisa é de natureza exploratória e utilizou uma abordagem mista, ou seja, uma abordagem quantitativa-qualitativa. De acordo com Creswell (2007), uma pesquisa mista envolve a coleta e análise de dados utilizando estratégias quantitativas e qualitativas. No caso desta pesquisa, os procedimentos foram sequenciais, iniciando com o método qualitativo para fins exploratórios, seguido do método quantitativo, usando uma grande amostra que tornou possível a generalização dos resultados. E, como procedimentos de coleta de dados, foram realizadas entrevistas com profissionais de psicologia (grupo A) e survey, com levantamentos através de questionários online ou impressos, com adolescentes/jovens (grupo B).

Foram selecionados seis psicólogos que atendiam ao público infanto-juvenil, sendo que apenas cinco permitiram o registro da entrevista. Destes, um trabalhava com crianças e adolescentes em uma casa de acolhimento, um realizava palestras e auxiliava em projetos numa cidade do interior de Alagoas, dois faziam parte do atendimento a adolescentes de instituições de ensino distintas (uma pública e uma particular) e dois trabalhavam em clínicas particulares (um destes não permitiu o registro da entrevista).

Em seguida, foram selecionadas três instituições públicas de ensino, por critérios de permissão de acesso e de representatividade da amostra, sendo uma da rede federal, uma estadual e uma municipal (duas em uma cidade de interior e uma na capital, todas em Alagoas) que autorizaram a visita e aplicação do questionário. A amostra desta etapa totalizou 566 indivíduos, com a faixa etária entre 12 e 21 anos.

O grupo A recebeu uma carta de apresentação, um termo de consentimento livre e esclarecido (TCLE), e uma cópia do questionário; sendo assim, cada um pôde decidir se permitiria ou não a realização da entrevista e seu registro. Por sua vez, as instituições responsáveis pelo grupo B receberam uma cópia da carta de apresentação e uma cópia do questionário aplicado aos adolescentes.

O questionário aplicado aos psicólogos (QP) entre os meses de setembro e outubro do ano 2018 foi composto por 12 questões abertas, o que proporcionou uma conversa franca e intensa sobre o tema da pesquisa. As questões foram baseadas nos resultados de uma Revisão Sistemática de Literatura (RSL), realizada por Souza e Cunha (2019), que indicaram que o uso excessivo das redes sociais digitais pode causar problemas sérios na saúde mental de adolescentes, levando-os a apresentar quadros de depressão e ideação suicida, advindos de ações perigosas no mundo virtual, como cyberbullying e grooming (assédio virtual).

O questionário aplicado aos adolescentes (QA) foi composto por 25 questões de múltipla escolha, sem identificação de nome do respondente. As questões foram criadas com base na referida RSL e na entrevista com os psicólogos. O QA foi aplicado em novembro de 2018, nas versões impresso e online; todos os questionários que foram respondidos de forma impressa foram repassados pela equipe para o formulário online. 
Os encontros para aplicação do QP foram realizados após um contato prévio com os profissionais, para apresentação da pesquisa e do seu objetivo. Foi solicitada e concedida a permissão para gravação das entrevistas. A seleção dos psicólogos foi feita através de indicações, usando a técnica de snowbolling.

\section{Resultados}

Esta seção apresenta os resultados das etapas qualitativa e quantitativa da pesquisa. Por motivo de restrição de espaço, apenas os quadros de respostas considerados mais relevantes serão exibidos na íntegra. As demais serão mencionadas de forma resumida.

A primeira questão buscou saber se os psicólogos estavam recebendo adolescentes/jovens nos consultórios com problemas psicológicos advindos do uso excessivo das redes sociais digitais. Dois respondentes disseram não ser um motivo muito comum, apesar de um deles ter destacado que a queixa maior é por parte dos pais ou responsáveis. Os demais responderam positivamente, com destaque para um deles que enfatizou que sim, principalmente por falta de concentração dos adolescentes e, consequentemente, baixo rendimento escolar e irritabilidade.

As respostas para a segunda questão, que refletiu sobre a identificação da dependência tecnológica em adolescentes e jovens, são apresentadas na Tabela 1. Quatro respondentes apontaram sinais visíveis para identificação da dependência, enquanto um deles sinalizou que a identificação só pode ser feita através dos sintomas e relatos verbalizados.

Tabela 1. Respostas dos psicólogos à Q2.

Como identificar a dependência tecnológica em adolescentes/jovens?

\begin{tabular}{cl}
\hline Psicólogo & \multicolumn{1}{c}{ Resposta } \\
\hline Psico1 & Tempo conectado; o quanto interfere (estudos, atividades e brincadeiras deixadas de lado). \\
\hline Psico2 & Através dos sintomas apresentados e relato de familiares e amigos. \\
\hline Psico3 & $\begin{array}{l}\text { Essa categorização é trazida mais pelos pais, que os chamam de viciados. Se o adolescente } \\
\text { consegue conviver com outros pares, amigos, em redes sociais, jogos, e isso não faz nenhum } \\
\text { mal radical, não há dependência. }\end{array}$ \\
\hline Psico4 & $\begin{array}{l}\text { Influência nos estudos (notas baixas, sem rotina, sem horário de estudo), no sono (estimulação } \\
\text { do cérebro por conta da luz azul) e no humor (irritabilidade). É como identificar um dependente } \\
\text { de álcool, deixa um tempo sem usar e vê o que acontece. Quando não consegue ficar sem o } \\
\text { celular, quando sente ansiedade por não estar com o aparelho. }\end{array}$ \\
\hline Psico5 & $\begin{array}{l}\text { A partir do momento que em o uso dessa tecnologia está afetando de forma negativa a sua } \\
\text { vida. No adolescente é possível ver a queda do rendimento escolar, estresse sem motivo } \\
\text { aparente e muitas vezes até insônia. }\end{array}$ \\
\hline
\end{tabular}

A terceira questão buscou formas de identificar riscos de depressão em adolescentes e jovens. Através das respostas dos psicólogos, resumidas na Tabela 2, é possível dizer que essa identificação varia de indivíduo para indivíduo, mas no geral, os riscos são detectáveis através de mudanças no comportamento e na maneira de socialização.

Tabela 2. Respostas dos psicólogos à Q3.

Como identificar um risco de depressão em adolescentes/jovens?

\begin{tabular}{ll}
\hline Psicólogo & Resposta \\
\hline Psico1 & $\begin{array}{l}\text { Isolamento social, deixar atividades antes prazerosas, pensamentos negativos, medo, } \\
\text { dificuldade em socializar. }\end{array}$ \\
\hline Psico2 & Observando seu comportamento e rede familiar. \\
\hline
\end{tabular}



Psico3 No geral, sem energia para fazer suas coisas, falta de apetite, que não está apto, sem testes (a psicanalise trabalha com as palavras), não se anima para fazer o que costuma fazer, mas é uma detecção a ser feita de maneira individual, pois cada um tem sua particularidade.
Psico4 Ficam mais introspectivos, não convivem em grupos sociais, muito apegado ao celular, postar que está bem quando não está, se tranca no quarto, não larga o celular, querer alcançar um padrão que é praticamente impossível, preocupação fútil com a aparência...
Psico5 Se o jovem aparentar desesperança, sentimento de inutilidade, pouca concentração, isolamento social, ideação suicida...

Para a quarta questão, que tratou da susceptibilidade dos adolescentes e jovens a problemas causados pelo uso das redes sociais, as respostas ficaram polarizadas entre sim e não. Já a quinta questão coletou informações mais enfáticas relacionadas ao bullying e ao cyberbullying (onde todos afirmaram receber algum tipo de relato). A sexta questão identificou que a maioria dos adolescentes e jovens enxerga as redes sociais digitais como solução para os seus problemas, onde podem encontrar um grupo com o qual se identifiquem, criar personagens fictícios e se proteger através deles.

A sétima questão tratou acerca da relação entre os adolescente e jovens com sua família ou amigos e foi unânime a afirmação de que o uso excessivo das mídias influencia no convívio social. Todos os psicólogos entrevistados citaram como essa relação social é afetada (Tabela 3).

Tabela 3. Respostas dos psicólogos à Q7.

É percebida alguma relação entre os adolescentes/jovens com alguma dificuldade no convívio social ou familiar e o uso excessivo das redes sociais? Se sim, qual?

\begin{tabular}{cl}
\hline Psicólogo & \multicolumn{1}{c}{ Resposta } \\
\hline Psico1 & Diretamente relacionada. Gera cobranças, que muitas vezes não são atendidas. \\
\hline Psico2 & Sim. A interação é prejudicada e nota-se isolamento. \\
\hline Psico3 & $\begin{array}{l}\text { Do que percebo, tem. Se a gente parar para problematizar, tem uma certa dificuldade, mas não } \\
\text { gosto de problematizar, fazem apenas uma pincelada. São questões de "inaptidão" para se } \\
\text { relacionar, e eles dizem não conseguir algo no mundo real, mas conseguem no virtual. }\end{array}$ \\
\hline Psico4 & $\begin{array}{l}\text { Sim. Fotos de restaurante onde cada um posta a foto do seu prato sem conversar com o outro, } \\
\text { conversas pelo whatsapp com pessoas que estão do lado, na mesma casa. }\end{array}$ \\
\hline Psico5 & $\begin{array}{l}\text { Bom... Com a tecnologia, as pessoas deixam de lado a comunicação com a família e passam } \\
\text { só a teclar. Nas saidinhas com os amigos, é possível ver que pelo menos um está com o celular } \\
\text { conversando com alguém que não este presente. Então, de certa forma, o uso das redes sociais } \\
\text { acaba desgastando esse contato olho no olho. Mas vale ressaltar que nem todo adolescente } \\
\text { que tenha dificuldade no convívio familiar ou social é, necessariamente, dependente das redes } \\
\text { sociais. }\end{array}$ \\
\hline
\end{tabular}

Sobre a oitava questão, os cinco psicólogos entrevistados afirmam que o uso das mídias só pode ser considerado saudável enquanto não afeta o convívio social real. A partir do momento que o indivíduo passa a admitir que as mídias interrompam suas atividades cotidianas, seus estudos e/ou trabalho, ele começa a tornar-se um usuário de risco, estando assim, mais acessível a problemas ocasionados pelo uso das redes sociais.

A Tabela 4 apresenta as respostas dos psicólogos para a nona questão, que versou sobre um paralelo entre os sintomas de dependentes de redes sociais e dependentes químicos. Alguns sintomas mencionados como comuns a ambos os casos foram: ansiedade, irritabilidade, abstinência, que podem causar danos à saúde física e mental.

Tabela 4. Respostas dos psicólogos à Q9.

\begin{tabular}{cc}
\hline $\begin{array}{c}\text { Algum dos sintomas presentes em dependentes químicos pode ser percebido em } \\
\text { adolescentes/jovens dependentes de redes sociais ou jogos virtuais? Quais? }\end{array}$ \\
\hline Psicólogo & Resposta \\
\hline
\end{tabular}




\begin{tabular}{ll}
\hline Psico1 & O principal é a ansiedade. \\
\hline Psico2 & Abstinência, tolerância, ansiedade. \\
\hline Psico3 & $\begin{array}{l}\text { A toxicomania é de uma outra classificação, mas pode ser feita a analogia como uma busca } \\
\text { por prazer, mesmo que essa busca seja destrutiva. Tem a ver com uma repetição. Busca por } \\
\text { uma satisfação que mesmo que faça mal, já sabendo que faz mal, mas já não consegue parar. }\end{array}$ \\
& O mal não é o objeto, só é mal se eu me relaciono mal com ele. \\
\hline Psico4 & Irritabilidade, sudorese, abstinência, taquicardia... Liberação de dopamina. \\
\hline Psico5 & $\begin{array}{l}\text { As alucinações, onde o dependente das redes sociais sente ou escuta o celular tocar ou vibrar, } \\
\text { quando na verdade nada disso está acontecendo. Há a busca daquilo que o dá prazer, porem } \\
\text { numa quantidade cada vez mais elevada, tem a perda de noção do tempo e quando não faz uso } \\
\text { da internet, fica irritado e muitas vezes agressivo. }\end{array}$ \\
\hline
\end{tabular}

A questão 10 tratou sobre a aplicabilidade da escala de Beck, cujas respostas indicaram que poderia ser utilizada, porém não isolada e sim acompanhada da observação; mas que desde o ano de 2018 foi retirada e não está sendo mais utilizada. A questão 11, buscou informações sobre a existência de testes ou escalas que avaliassem a relação das mídias com problemas psicológicos. No entanto, nenhum dos psicólogos entrevistados conhecia qualquer ferramenta de avaliação para este tema. Já em relação à questão 12, todos atribuíram a responsabilidade aos pais sobre a fiscalização/monitoramento do acesso à internet e a respectiva delimitação do tempo.

Em relação à etapa quantitativa da pesquisa, a amostra foi obtida em três instituições públicas de ensino (federal, estadual e municipal) e totalizou 566 adolescentes e jovens com a faixa etária entre 12 e 21 anos. Também por questões de espaço, alguns gráficos foram suprimidos, ficando apenas o relato dos resultados.

A amostra foi composta por $14 \%$ alunos de uma escola estadual, $40 \%$ de uma escola federal e $46 \%$ de uma escola municipal. As turmas variaram do $6^{\circ}$ ano do ensino fundamental até o $4^{\circ}$ ano do ensino médio/técnico. A pesquisa contou com $50 \%$ do sexo feminino, $46 \%$ do sexo masculino e os demais não se posicionaram quanto ao gênero. Do total de alunos participantes da pesquisa, $25 \%$ tinham entre 12 e 14 anos de idade, $56 \%$ entre 15 e 17 anos, e $19 \%$ entre 18 e 21 anos, na época em que foi realizada a pesquisa.

Inicialmente os indivíduos foram questionados se preferiam ficar em casa acessando as redes sociais ou sair com os amigos. Apenas 19\% responderam que preferiam acessar as redes sociais que sair com os amigos. Em seguida, foram questionados sobre o que consideram ser mais importante ao postar ou compartilhar uma foto nas redes sociais (Figura 1). A maioria, 63\%, informou que seria registrar o momento ao postar uma foto, $19 \%$ alcançar o maior número de curtidas, $16 \%$ mostrar aos outros aqueles determinados momentos, roupa ou qualquer outra coisa que exista na imagem e $2 \%$ apontaram o desejo por grande número de comentários.

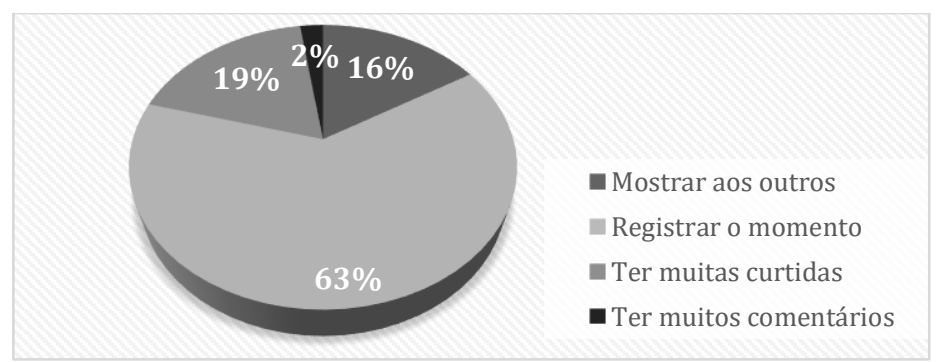

Figura 1. 0 que é mais importante ao postar fotos nas redes sociais? 
A terceira questão abordou sobre qual o ambiente onde se sentem mais seguros (Figura 2). 14\% afirmaram que se sentem mais seguros no mundo virtual, 15\% disseram que se sentem seguros tanto no mundo real quanto no virtual, $71 \%$ não se sentem seguros na internet, sendo que destes, $35 \%$ também não se sentem seguros no mundo real.

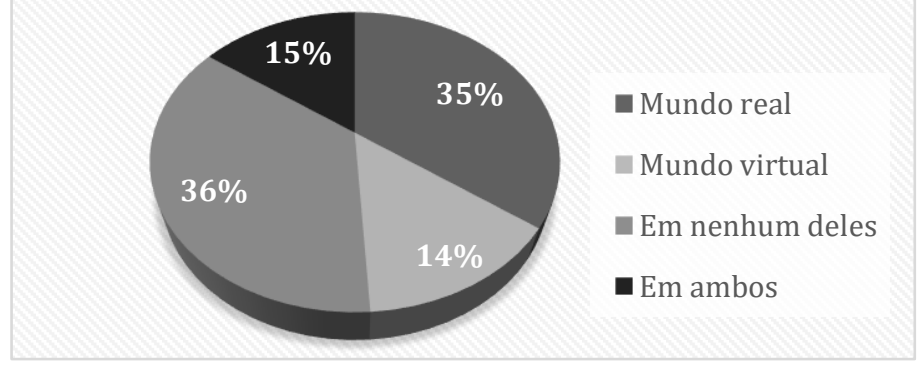

Figura 2. Em qual ambiente se sentem mais seguros: real ou virtual?

A quarta questão versou sobre a permissão de visualização das próprias postagens nas redes sociais digitais. 52\% afirmaram que não permitem que desconhecidos tenham acesso às suas postagens e $48 \%$ afirmaram que permitem o acesso a qualquer pessoa, independentemente de estarem na sua lista de amigos/conhecidos.

Quando os adolescentes foram perguntados se recebiam reclamações devido ao tempo que passavam conectados (Figura 3), foi possível observar que, apenas $8 \%$ dos respondentes nunca receberam reclamações devido ao tempo conectados.

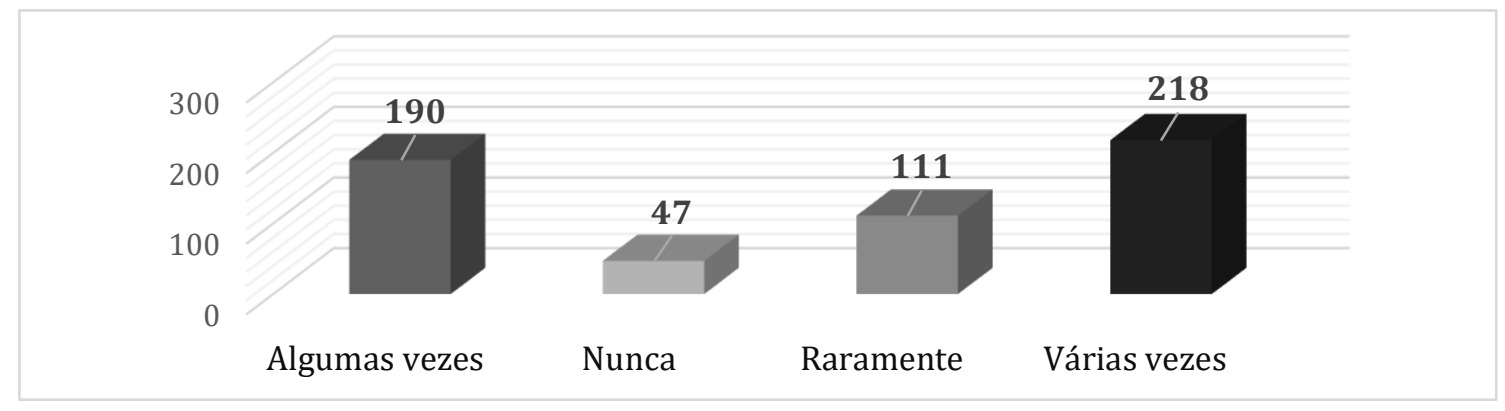

Figura 3. Reclamações quanto ao tempo que permanecem conectados.

A questão seguinte solicitou que os respondentes informassem a intensidade, em uma escala de zero a cinco, de uso de cada rede social digital. As redes que mais se destacaram, sinalizadas com a mais alta intensidade, foram whatsapp $(61 \%)$, seguida do instagram (33\%). A sétima, procurou mensurar a frequência com a qual os respondentes utilizavam as mídias sociais (Figura 4 ). 42\% responderam mais de cinco horas por dia.

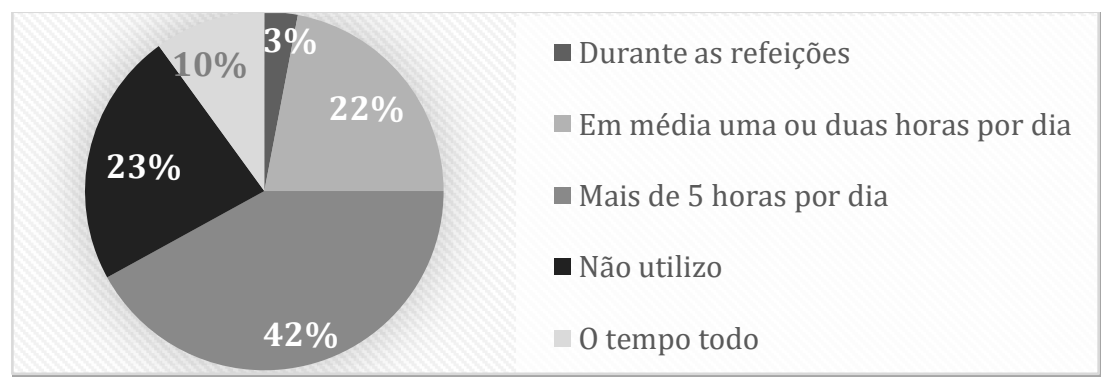

Figura 4. Frequência de uso das mídias sociais. 
A oitava questão abordou sobre a motivação para utilizar as redes sociais virtuais. $74 \%$ afirmaram que se trata de manter a comunicação e troca de mensagens e 55,3\% como uma maneira de passar o tempo (Figura 5). Para esta questão foi permitido a opção por mais de uma alternativa, se assim desejassem.

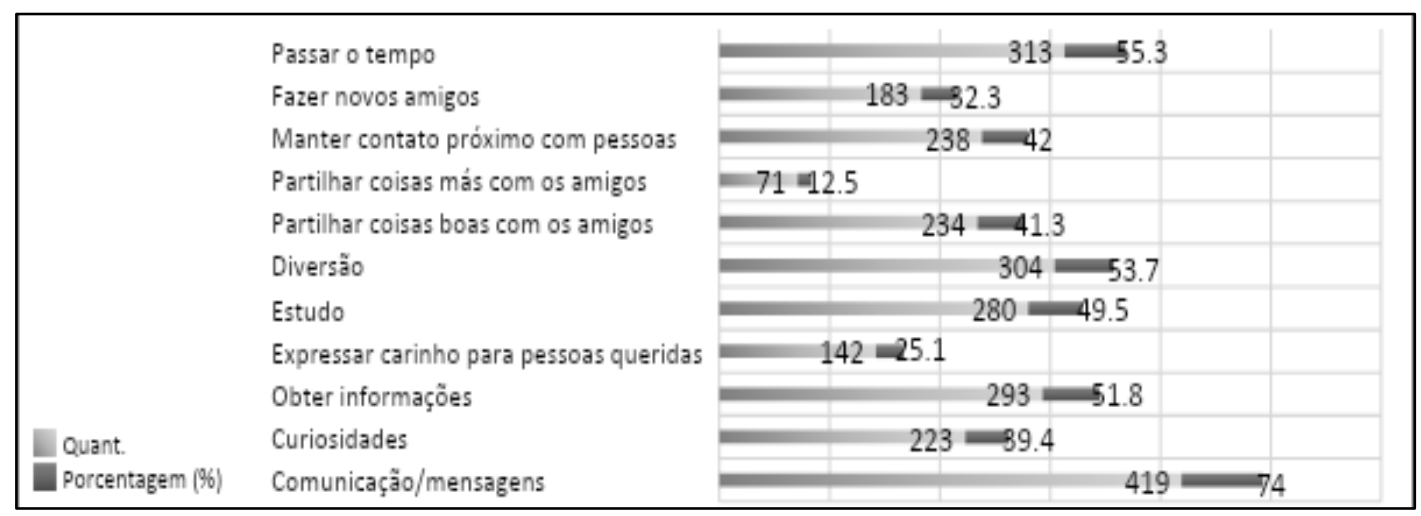

Figura 5. Motivação para o uso das mídias sociais.

A questão seguinte abordou sobre o tipo de equipamento mais utilizado para acesso à internet, $90 \%$ dos respondentes indicaram o celular.

As mensagens recebidas através de redes sociais virtuais podem muitas vezes ser mal interpretadas, sendo assim, a pergunta 10 questionou "você considera que compreende completamente as mensagens que recebe?" e 51\% afirmaram que não compreendem ou que apenas algumas vezes conseguem compreender as mensagens recebidas.

A questão 11 tratou de identificar em que intensidade os respondentes costumam compartilhar seus sentimentos online. Quase $60 \%$ informaram que às vezes ou sempre compartilham seus sentimentos. A amostra revela que a maioria dos adolescentes e jovens expõem seus sentimentos e, por conseguinte, as suas vulnerabilidades, nas redes sociais.

A questão 12 aferiu sobre o uso dos aparelhos celulares durante as aulas. 55\% indicaram que não usam celular durante as aulas (em parte, isso ocorre devido a proibição em uma das escolas) e $23 \%$ afirmaram que usam por causa da falta de atratividade da aula e dos conteúdos trabalhados.

A questão 13, abordou quanto ao uso de celular no horário referente ao intervalo das aulas. 51\% disseram que não o utilizam nos intervalos, $17 \%$ afirmaram que usam pelo hábito de estarem no celular e $15 \%$ disseram que usam porque não têm o que fazer. Os outros $17 \%$ afirmaram que usam por não ter amigos, necessidade de resolver assuntos ou problemas reais, saber das novidades nas redes sociais ou por timidez.

A questão 14 procurou aferir se os respondentes sentem solidão quando não possuem acesso à internet e/ou redes sociais. 46\% negaram qualquer sentimento de solidão, e 16\% afirmaram sentir solidão quando não possuem acesso, e 38\% disseram que às vezes sentem-se sozinhos.

Como resposta à questão 15 , os dados revelaram que $54 \%$ dos respondentes nunca utilizam a internet apenas pelo tempo programado, sempre ultrapassam; 36\% disseram que às vezes passam do tempo programado; e apenas $10 \%$ informaram ter controle sob o uso da internet, utilizando-a apenas pelo tempo que programa ou combina com os pais ou 
responsáveis. Os resultados revelam o potencial de distração que existe nas redes sociais em detrimento de outras atividades.

A questão 16, por sua vez, abordou se os adolescentes e jovens têm o costume de se atrasar em compromissos por ficarem conectados às redes sociais. 51\% negaram atrasos recorrentes por este motivo, enquanto $22 \%$ afirmaram que isso acontece com frequência.

A questão 17 (Figura 6) foi direcionada para a identificação dos sentimentos do interlocutor. Das quatro opções oferecidas para esta questão, 54\% informaram que conseguem identificar os sentimentos do interlocutor em qualquer situação.

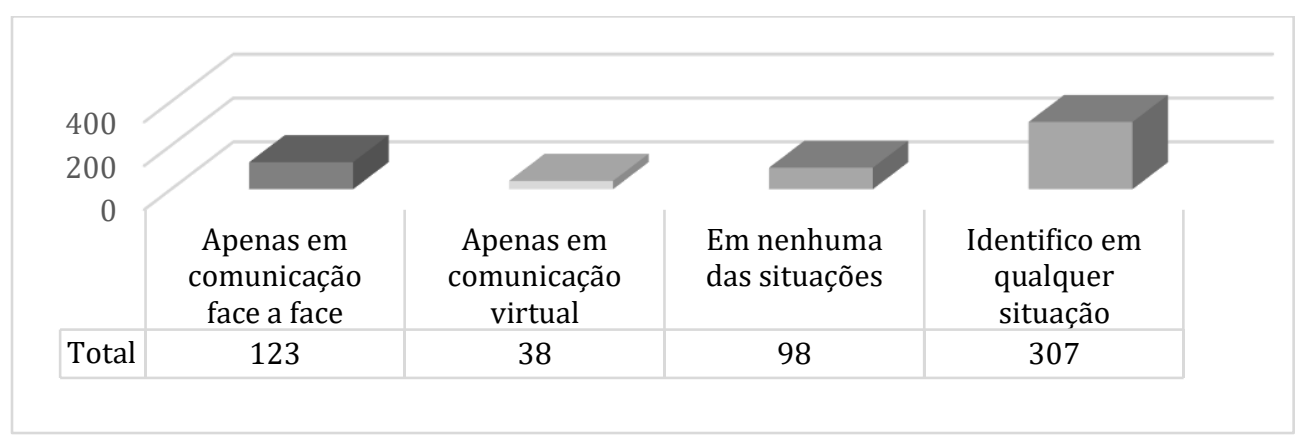

Figura 6. Identificação dos sentimentos do interlocutor.

Os resultados obtidos para a questão 18 da pesquisa com os adolescentes e jovens apontaram que 39\% utilizam os emoticons para expressar seus sentimentos, 38\% indicaram que às vezes fazem uso dos emoticons, enquanto $23 \%$ negaram usá-los.

Ao serem questionados sobre "com quem se comunicam", na questão 19 (Figura 7), com a possibilidade de selecionar mais de uma opção, $85,5 \%$ responderam com os amigos.

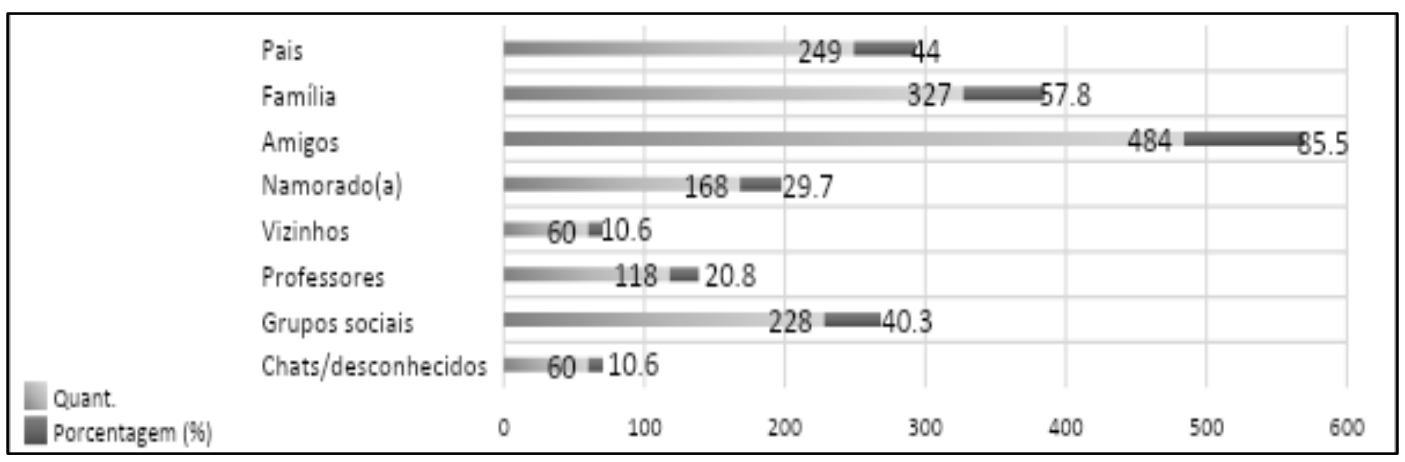

Figura 7 - Com quem se comunicam nas redes sociais.

$\mathrm{Na} 20^{\mathrm{a}}$ questão os adolescentes e jovens foram indagados sobre como se sentem quando suas mensagens não são respondidas, ou quando suas postagens não são comentadas (Figura 8). A maioria respondeu que sentem tranquilidade e que não se abalam com a falta de comentários ou curtidas. Mas existe um contingente que se manifestou como irritado, frustrado, ansioso e tenso. Esses são os que precisam ser monitorados e ajudados. 


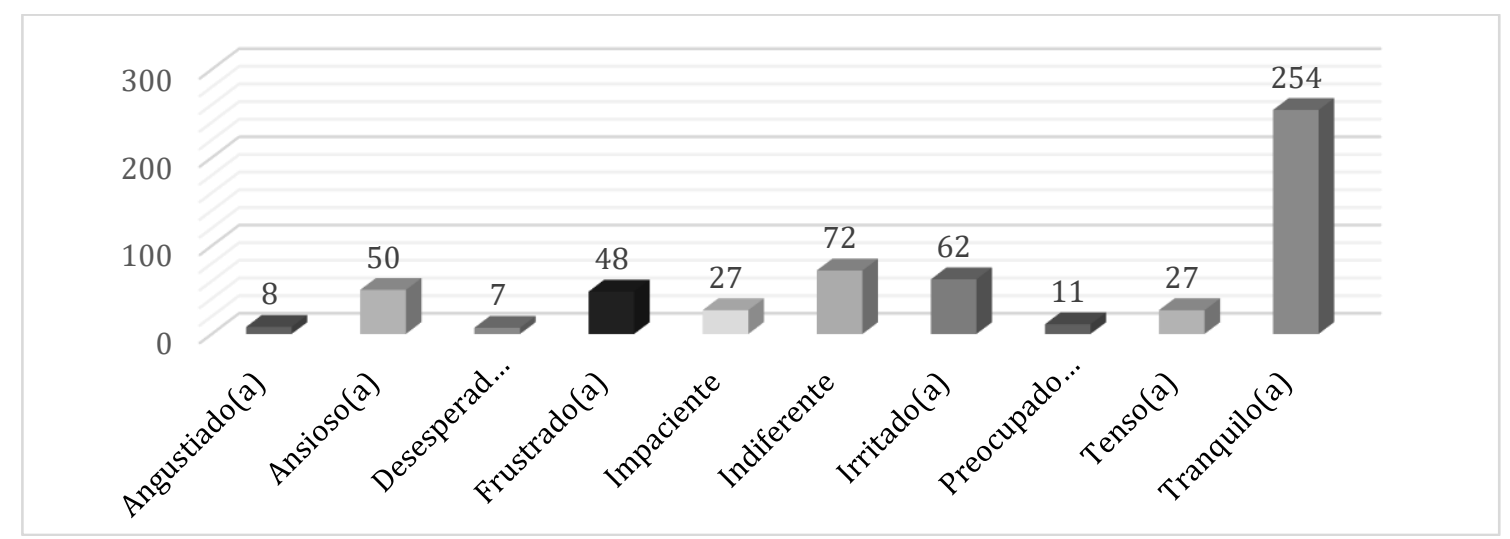

Figura 8 - sentimento ao não receber comentários nas redes sociais.

A questão 21 abordou o sentimento que os adolescentes/jovens nutrem ao receber respostas ou comentários. $51 \%$ afirmaram se sentirem tranquilos ao terem as mensagens respondidas ou seus posts comentados, e $34 \%$ assinalaram que se sentem contentes.

A Figura 9 apresenta as respostas para a questão 22, sobre como os indivíduos se sentem quando ficam sem dispositivos de acesso à internet. Dentre as respostas mais expressivas, $30 \%$ disseram que se sentem tranquilos, $20 \%$ impacientes e $10 \%$ sentem-se ansiosos. Importante perceber que aqueles que sinalizaram sentimentos mais negativos compõem a maioria dos respondentes, outro sinal de alerta que essa geração traz à tona.

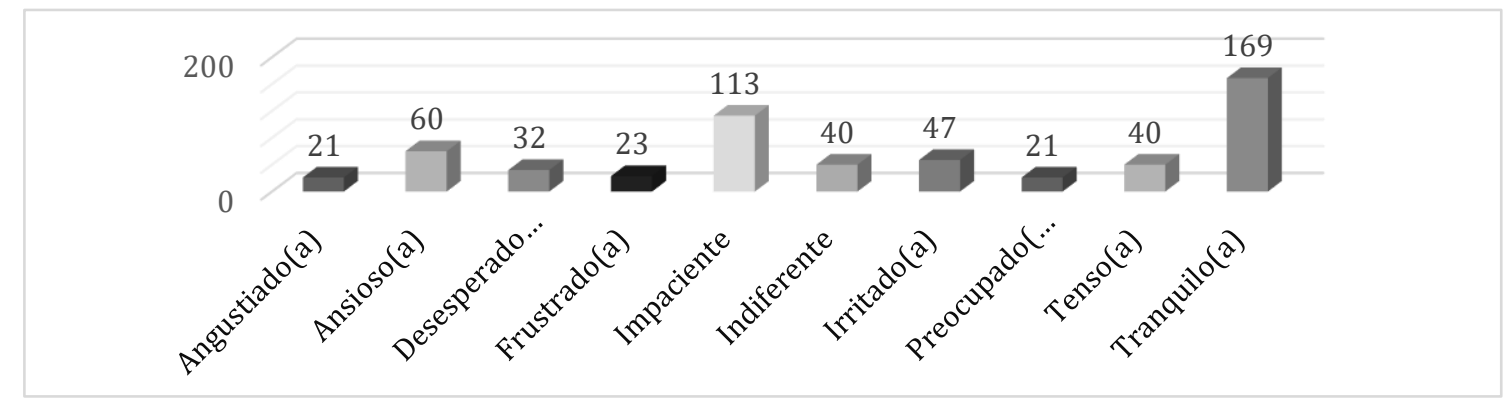

Figura 9. Sobre como os adolescentes/jovens se sentem sem dispositivos conectados à internet.

A questão seguinte procurou analisar quais as situações onde os adolescentes e jovens sentem maior necessidade de usar as redes sociais digitais. 37\% afirmaram que sempre, em todo momento, sem um motivo específico ou aparente; enquanto $26 \%$ alegaram outros motivos diferentes das opções propostas.

Sobre a maneira através da qual preferem se comunicar abordada na questão 24 , $57 \%$ dos respondentes indicaram que preferem o contato pessoal, enquanto $30 \%$ demonstrou preferência por mensagens escritas. Já sinalizando uma preocupação com essas relações virtuais que alguns preferem ter.

A questão 25, cujos resultados são exibidos na Figura 10, interrogou sobre o tempo que os indivíduos levam para pedir a senha do wi-fi em locais públicos. $37 \%$ responderam que não pedem a senha, provavelmente porque já possuem em seu celular um plano de dados, e $51 \%$ responderam que pedem assim que chegam ou, no máximo, em até 30 minutos. 


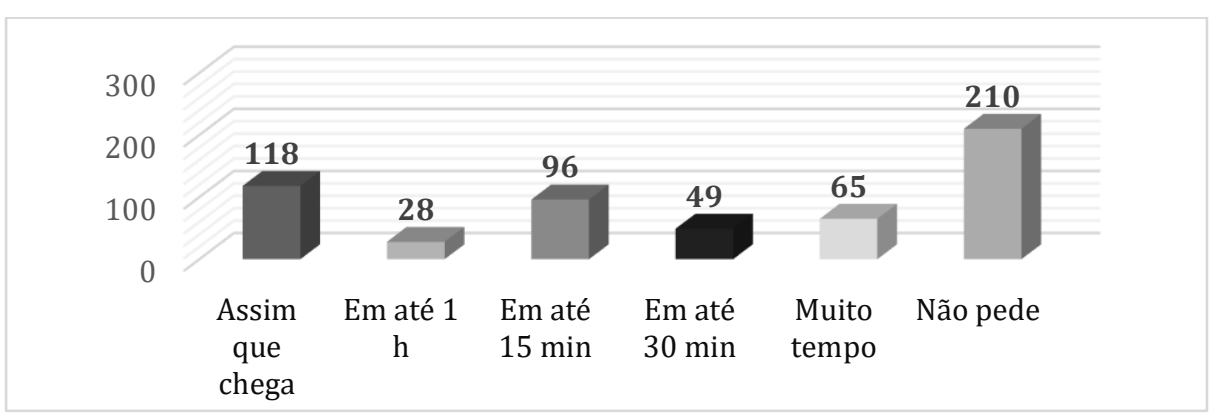

Figura 10 - Tempo que levam para pedir a senha do wi-fi em locais públicos.

Os resultados desta pesquisa se apresentaram similares aos resultados de trabalhos como o de Silva et al (2017). Os autores apontaram que a maioria dos adolescentes com acesso à internet passavam mais de 10 horas conectados, geralmente utilizando os smartphones para a conexão. Assim como no trabalho de Fialho e Sousa (2019), foi possível notar que os adolescentes usavam a internet para acessar as redes sociais, e muitas vezes sem orientação por parte dos pais e da escola.

\section{Conclusões}

As opiniões dos psicólogos forneceram aprendizado e enriqueceram o trabalho, guiando caminhos para a elaboração do survey aplicado posteriormente aos adolescentes e jovens. Através das entrevistas foi possível compreender melhor o tema e encontrar melhores maneiras de abordá-lo nas escolas.

Por meio das conversas com os respondentes do QP foi possível identificar que muitos adolescentes são dependentes tecnológicos, mas que muitas vezes não interpretam o uso excessivo das redes sociais digitais como problema, logo que no mundo virtual encontram soluções e procuram se adaptar aos padrões de uma sociedade "perfeita". Os impactos negativos do uso excessivo das tecnologias são camuflados pelas diversas vantagens apresentadas pelos dispositivos, as distrações oferecidas pelas redes sociais digitais transformam momentos de lazer em horas de distanciamento social, como foi possível confirmar durante a pesquisa, quando 54\% dos adolescentes e jovens respondentes afirmaram que passam mais tempo conectados do que o programado.

Comparando as respostas do survey com trabalhos correlatos, foi possível perceber que $40 \%$ dos adolescentes e jovens apresentaram quadros que merecem monitoramento, tendo em vista que seus sentimentos se assemelham aos de um dependente químico. Percebeu-se que devido a pesquisa ter sido aplicada em um contexto escolar, muitos alegaram não usar o celular durante as aulas, mas na verdade, quando eles não são proibidos pelos professores, usam abertamente as redes sociais digitais em sala de aula. Além disso, outro dado peculiar foi que na pesquisa de Silva et al. (2017) a maioria dos entrevistados alegou passar mais de 10 horas conectado e nesta pesquisa o índice foi $42 \%$ acima de cinco horas.

A maior preocupação está nos excessos, para que esses indivíduos não venham a sofrer consequências graves devido ao uso indevido das redes sociais digitais. Os conhecimentos adquiridos no universo desta pesquisa de campo serviram como base para a proposição de um aplicativo, chamado Girassol (SOUZA; CUNHA; SANTIAGO, 2019), voltado para detectar, a partir de perguntas correlacionadas a esta pesquisa, possíveis riscos de dependência tecnológica. Cabe ressaltar a importância do pesquisador 
ir a campo e enxergar as particularidades do universo multidisciplinar, a fim de delinear uma proposta de aplicativo que seja alinhada com as demandas e próxima da realidade dos futuros usuários. No caso desta pesquisa, próxima da realidade dos adolescentes e jovens, bem como dos professores e psicólogos escolares que podem utilizar o fascínio deste público pela tecnologia para identificar, de forma lúdica e indireta, quem precisa de ajuda psicológica.

Como trabalhos futuros, sugere-se que esta pesquisa seja replicada em outros contextos escolares, com o objetivo de analisar e atualizar informações sobre os quadros de dependência tecnológica nos ambientes educacionais, comparando os resultados e averiguando os níveis de dependência dos adolescentes no decorrer dos anos.

\section{Referências}

BLACHNIO, A. et al. (2015). Internet use, Facebook intrusion, and depression: results of a crosssectional study. European Psychiatry, v. 30, n. 6, p. 681-684.

CRESWELL, J. W. (2007). Projeto de pesquisa: métodos qualitativo, quantitativo e misto. 2. ed. Porto Alegre: Artmed.

FIALHO, L. M.; SOUSA, F. G. A. (2019) Juventudes e redes sociais: interações e orientações educacionais. Revista Exitus, Santarém/PA, v. 9, nº 1, p.202-231.

GONÇALVES, B. G.; NUEMBERG, D. (2012) A dependência dos adolescentes ao mundo virtual. Revista de Ciências Humanas, Florianópolis, v. 46, nº 1, p.165-182.

RADOVIC, A.; et al. (2017) "Depressed Adolescents' Positive and Negative Use of Social Media." Journal of adolescence 55: 5-15. PMC.

SAMPASA-KANYINGA, H.; HAMILTON, H. A. (2015). Social networking sites and mental health problems in adolescents: The mediating role of cyberbullying victimization. European psychiatry, v. 30, n. 8, p. 1021-1027.

SILVA, A. P. A. (2016). As implicações do uso da rede social Facebook para a felicidade dos adolescentes. Dissertação (Mestrado em Gestão Comercial) Faculdade de Economia, Universidade do Porto, Portugal.

SILVA, T. O.; SILVA, L. T. G. (2017). Os impactos sociais, cognitivos e afetivos sobre a geração de adolescentes conectados às tecnologias digitais. Revista Psicopedagogia, São Paulo, v. 34, n. 103, p. 87-97.

SILVA, R. A.; et al. (2017). Adolescentes e abuso de tecnologias: um indicativo de problemas comportamentais? Adolescência e Saúde, Rio de Janeiro, v. 14, no 3, p. 77 82.

SOUZA, K.; CUNHA, M. X. C. (2019). Impactos do uso das redes sociais virtuais na saúde mental dos adolescentes: uma revisão sistemática da literatura. Educação, Psicologia e Interfaces, v. 3, n.3, p. 204-217.

SOUZA, K. D.; CUNHA, M. X. C.; SANTIAGO, E. D. (2019) Girassol: Um aplicativo móvel para medir níveis de dependência tecnológica em adolescentes e jovens. In: Escola Regional de Computação Bahia Alagoas Sergipe, 19, Ilhéus, BA. Anais... Disponível em https://sol.sbc.org.br/index.php/erbase/article/view/8995/8896. 